Documentos

\title{
El narcotráfico en la proyección internacional de la situación interna de Colombia
}

\author{
Anibal Palma Fourcade
}

La situación interna de Colombia concita la atención internacional y preocupa no sólo a los países de su entorno geográfico, sino también a naciones de otros continentes que de una $u$ otra forma se sienten amenazadas o afectadas por su proyección externa.

Es un fenómeno relativamente reciente que no se había manifestado antes con amplitud y la intensidad que se aprecia en el último tiempo. Declaraciones de Jefes de Estado y de autoridades de distintos Gobiernos, resoluciones de Organismos Internacionales y de instituciones de la más diversa índole, constituyen una demostración fehaciente de que la situación por la que atraviesa este país ha pasado a ser un problema que trasciende sus fronteras. Surgen así distintas propuestas que generan polémica y que van desde las voces que claman por una intervención militar a los que apuestan por la capacidad de su gobierno para encontrar un camino de solución.

Frente a este panorama, se nos plantea una primera interrogante. Si la actividad guerrillera en Colombia se extiende por más de cuarenta años, si la violencia es una constante en su desarrollo histórico, especialmente a partir de los años 30 del siglo XX, si el cultivo, elaboración y tráfico de la droga ocupa un lugar prominente en el escenario de las últimas décadas, ¿̨por qué se plantea ahora con la intensidad que conocemos la preocupación por su problemática interna?, o en otros términos, ¿por qué se le atribuye a ésta una 
gravedad que hace que algunos la consideren una amenaza regional y otros un factor de desestabilización que no reconoce límites?

La explicación de este fenómeno no es fácil ni puede atribuirse a una sola causa. Son múltiples los elementos que influyen en su génesis y desarrollo.

Por encima de la guerrilla, los paramilitares, la violencia, la corrupción, la crisis económica, la debilidad institucional, pensamos que el narcotráfico, con sus múltiples ramificaciones, constituye el factor principal por cuanto incide con fuerza en los otros, penetra en los distintos estamentos del país y se proyecta en el plano internacional con una gravitación de tal magnitud, que lo transforma en una amenaza frente a la cual ninguna nación puede sentirse inmune.

\section{Narcotráfico, guerilla y paramilitares}

Entre actores tan disímiles como la guerrilla, los paramilitares y el narcotráfico, se produce una «asociación natural». Lo que parece difícil de entender, tiene sin embargo, una explicación simple. Los cultivos de marihuana, coca o amapola, se extienden en zonas donde no llega la autoridad o que le son de muy difícil acceso. Lo mismo ocurre con la instalación de laboratorios para el procesamiento y elaboración de la droga, los depósitos para su almacenamiento, las pistas de aterrizaje y otras vías para su traslado.

Esas zonas coinciden con aquellas en que opera o están bajo control de la guerrilla. La convivencia forzada que esta situación genera una diversificación de funciones. No es que los guerrilleros se transformen en narcotraficantes, ni éstos en integrantes de esas organizaciones subversivas. Cada uno se dedica a la actividad de su especialidad, para la que están más preparados y tienen mayor experiencia y contactos, actividades que se complementan y que son funcionales unas a las otras.

La guerrilla constituye un escudo natural que protege el cultivo, elaboración y traslado de la droga. Cobra por ello un impuesto de acuerdo a la extensión de las plantaciones, el volumen producido y los medios dedicados a su transporte. Los narcotraficantes cancelan lo que se les cobra sin que esto afecte mayormente sus costos, pues si no existiera la guerrilla tendrían que invertir en financiar ejércitos privados que les dieran la protección que ésta les brinda.

No obstante lo anterior, los guerrilleros no se consideran traficantes de droga. Sostienen con una argumentación que puede parecer ingenua o cínica, 
pero que para ellos es convincente y los justifica, que también cobran impuesto a los agricultores por hectárea sembrada, a los ganaderos por cabeza de ganado, a los transportistas por vehículo que transita por los caminos que controlan, a las industrias instaladas en las regiones en que actúan y no por eso son agricultores, ganaderos, transportistas o industriales. En todo caso, cualquiera que sea la explicación, es evidente que el dinero que les reporta el narcotráfico constituye su mayor y más directa fuente de ingresos, por lo que no les resulta fácil renunciar o prescindir de ellos.

Por otra parte, cabe agregar que esa «asociación natural» permite también economizar en otros rubros como el transporte. Los mismos medios utilizados para sacar la droga, se utilizan para ingresar insumos y armamento.

Lo dicho respecto a las organizaciones guerrilleras, es válido también para los paramilitares en su asociación con el narcotráfico, aunque éstos no se hacen mayor problema en dar explicaciones o autojustificarse.

\section{Narcotráfico y violencia}

La violencia en Colombia, que como hemos señalado anteriormente, constituye una constante en su historia reciente, no se origina en el narcotráfico ni es éste el principal factor que la produce. Mayor influencia tiene indudablemente la acción de la guerrilla y de los paramilitares, pero el narcotráfico se ha constituido en un elemento importante en su intensidad y desarrollo. A título de ejemplo, bastaría con señalar que una de las peores expresiones de violencia que se han registrado en este país, fue el terrorismo indiscriminado desatado por Pablo Escobar, jefe del Cartel de Medellín, en su guerra privada contra el Estado.

El narcotráfico, en cualquier país en que opere, conlleva distintas formas de violencia, desde la presión y la amenaza, hasta el asesinato individual o colectivo. Mediante ella se defienden o se ganan mercados y territorios, cultivos y laboratorios, se compra protección, se controlan rutas, medios de transporte y vías de acceso, se castiga a quienes traicionan, delatan o transgreden sus normas. Para estos fines, la utilización de sicarios encuentra en la mafia y en los capos de la droga sus principales promotores y financistas.

Pero lo más grave, es que estos mismos métodos, sumados a la corrupción, son utilizados para penetrar actividades económicas legítimas y ejercer 
una presión indebida sobre autoridades y ciudadanos. No es menor en consecuencia, la responsabilidad del narcotráfico en la violencia que ha pasado a ser un signo distintivo de Colombia.

\section{Narcotráfico y corrupción}

La corrupción y sus nefastas consecuencias están indisolublemente unidas al negocio de la droga. No es necesario extenderse para destacar la gravedad que esto implica, pues ha llegado, a considerarse una seria amenaza para la estabilidad institucional de los países.

Colombia es un ejemplo preocupante. Las recientes acusaciones de utilización de dineros provenientes del narcotráfico para el financiamiento de candidaturas presidenciales y parlamentarias y para el soborno de legisladores, miembros del poder judicial, autoridades de gobierno, personeros de las Fuerzas Armadas, periodistas, empresarios, deportistas y otros representantes del mundo político, económico y social, ponen de manifiesto como el narcotráfico contamina los diversos estratos de la sociedad colombiana.

Las revelaciones surgidas de las investigaciones realizadas, de las condenas judiciales y de los procesos en desarrollo, demuestran el grado de influencia que los grandes carteles de la droga lograron sobre la actividad del país. Es cierto que la desarticulación de sus principales organizaciones, el encarcelamiento de los capos más importantes, la extradición de algunos de ellos a los Estados Unidos, la mayor eficacia policial y un control más riguroso del lavado de dinero, ha disminuido esa influencia. Ha contribuido también a ello la toma de conciencia de la sociedad en su conjunto sobre la gravedad de este problema que afecta la economía del país y su credibilidad y prestigio en el plano internacional.

Sin embargo, las estadísticas muestran un aumento en la extensión de los cultivos y en la producción de droga. Organizaciones más pequeñas y por consiguiente más difíciles de detectar, han reemplazado a los grandes carteles. Los nuevos capos han aprendido la lección y se muestran más discretos y cautelosos en su accionar. En consecuencia, el problema persiste y con la corrupción se mantiene y extiende. 


\section{Narcotráfico y crísis económica}

Las frías cifras de las estadísticas mostraron un panorama desolador de la economía colombiana para el año 1999. Se proyectó una caída del Producto Interno Bruto del 3\%. La tasa de desempleo alcanzó en el tercer trimestre a un 20,1\%, el más alto de América Latina. Esto significa que 1.420 .000 colombianos se encuentran sin trabajo, a lo que se suma un subempleo que se calcula en un 22,6\%. La inflación estimada era relativamente baja - $11 \%$ pero más que un signo positivo, es una expresión más de la recesión económica que vive este país. Las reservas internacionales disminuyeron $860 \mathrm{mi}-$ llones de dólares en los primeros ocho meses, mientras el gobierno reconoce que el déficit fiscal para ese año representaría un 4,5\% del PIB.

El narcotráfico tiene una fuerte incidencia en esta situación. Durante años, las enormes cantidades de dinero generadas del negocio de la droga que se lavaban y se invertían en Colombia, dieron lugar a un auge económico artificial, especialmente en el área de la construcción que por su efecto multiplicador impulsaba otras actividades y producía una fuerte demanda de mano de obra. Adicionalmente el comercio se veía también favorecido.

La desarticulación de los principales carteles y un control más estricto, disminuyeron sensiblemente esas inversiones. Esto se tradujo en una fuerte contracción de la actividad económica en diversas ciudades y regiones con el consecuente aumento del desempleo. Una muestra evidente de lo dicho la encontramos en la paralización de numerosas obras y construcciones en centros urbanos importantes como Cali y Medellín.

A lo anterior, se suma la reticencia de muchos empresarios a invertir y expandir sus negocios, por temor a ser víctimas de la presión de los nuevos capos que procuran legitimar sus ganancias ilícitas aportando capital o incorporándose como socios en actividades que no despierten sospechas.

El comercio por su parte, se ve enfrentado a la competencia desleal del contrabando, mal endémico en Colombia, que ha adquirido en el último tiempo una dimensión desmesurada. Esto por cuanto el contrabando se ha transformado en uno de los mecanismos más utilizados para el lavado de dinero. La operación es sencilla. Se adquiere en la zona libre de Colón en Panamá, o en otras de similares características, electrodomésticos, vestuario, implementos deportivos, equipos electrónicos, licores y otros productos de fácil comercialización que son introducidos sin pagar impuestos. Los dólares con que se 
adquieren esos productos en el exterior, se transforman en pesos colombianos al venderse en el país.

Como éstos, podríamos citar otros ejemplos de la incidencia del narcotráfico en la situación económica colombiana, que por cierto se suma a otras causas de tanta o mayor importancia pero cuyo análisis escapa al marco de este trabajo.

\section{Narcotráfico y debilitamiento de la institucionalidad}

Es un hecho que la institucionalidad colombiana se ha debilitado como resultado de un proceso de larga data en que han influido múltiples situaciones: la incapacidad para frenar el avance y fortalecimiento de la guerrilla; la extensión de la violencia y la corrupción; el cuestionamiento cada vez más fuerte a la clase política; la sensación de ineficacia de un congreso en el que muchos de sus integrantes, enredados en rencillas y polémicas personales, no están a la altura de lo que el país les demanda; la desconfianza en el poder judicial y el cansancio por lo complejo y lento de sus procedimientos; las acusaciones de violación a los derechos humanos y de complicidad con los paramilitares que afectan a las Fuerza Armadas; las promesas de reforma y de cambio formuladas por los gobiernos de turno que no se concretan; los cargos que se hacen a numerosas autoridades por abusar de sus privilegios; los múltiples procesos por enriquecimiento ilícito que involucran a personeros de las más diversas instituciones; la ausencia de representantes del Estado en amplias regiones del territorio; la sensación de inseguridad que se vive en las ciudades por el aumento de la delincuencia, del terrorismo y la acción de sicarios que asesinan por encargo; el incremento de los secuestros que se ha transformado en una amenaza permanente que atemoriza a todos; la falta de liderazgos para encausar los grandes anhelos de la sociedad, especialmente en su reclamo de paz, que han sido parcialmente suplidos por representantes de la sociedad civil.

La enumeración anterior no agota las causas de este proceso, pero indudablemente el narcotráfico es una de las que gravita con mayor fuerza. Su enorme poder económico le permite utilizar la corrupción como instrumento para el desarrollo de sus actividades. El proceso 8.000 , que investiga la extensión de este fenómeno, ha puesto en evidencia una realidad parcialmente 
conocida, pero cuya magnitud no se percibía. Ningún sector de la sociedad colombiana pareciera haber quedado inmune a la influencia del dinero del narcotráfico.

El impacto de las revelaciones del mencionado proceso ha provocado un fuerte deterioro en la credibilidad de las autoridades y de la confianza en las instituciones del Estado.

En el plano internacional, este problema adquiere una dimensión aún mayor sobre la que no es necesario extenderse. La realización de este Seminario es una expresión más, entre tantas otras, de la preocupación por esta realidad.

\section{A modo de conclusión}

Como podemos apreciar del resumen que antecede, el narcotráfico está presente, con mayor o menor gravitación, en los principales factores que inciden en la delicada situación interna de este país y ha pasado a visualizarse como la amenaza más grave por otras naciones.

No es la guerrilla como en la década de los 60 y 70 lo que más preocupa a los países limítrofes y a otros de éste y más lejanos continentes. Superada la Guerra Fría y la confrontación ideológica, en un mundo que dejó de ser bipolar, la guerrilla no es considerada un problema que pueda extenderse a otras regiones, poniendo en peligro la estabilidad de sus gobiernos o transformarse en una amenaza para un determinado sistema de dominación o modelo económico. Esto sin perjuicio que sus operaciones en zonas fronterizas, incorporan un elemento más de tensión y conflicto en la relación bilateral con los países vecinos.

Pero no es sólo el mundo el que ha cambiado. La guerrilla tampoco es la misma. La ideologización que la caracterizaba en el pasado, ha cedido espacio importante a un pragmatismo que la lleva a utilizar el poder para controlar territorios y poblaciones más que como instrumento para impulsar cambios revolucionarios que hagan posible la construcción de una nueva sociedad. No reconoce tampoco líderes y paradigmas más allá de sus fronteras. Sus dirigentes más lúcidos asumen que el derrumbe del llamado socialismo real, la globalización, los cambios de modelo económico y otras transformaciones que en forma vertiginosa se han sucedido en el mundo en los últimos años, hacen muy difícil, por no decir imposible, una victoria militar y con ella el control del Estado. 
Es significativo también el cambio en la posición de los Estados Unidos frente a la guerrilla. En el pasado la combatió por todos los medios, incluso en el plano ideológico acuñando la tesis del enemigo interno, mientras que en el terreno militar orientaba el adiestramiento de los ejércitos de América Latina a la lucha antisubversiva. En la actualidad, ha dejado de figurar entre sus preocupaciones más importantes.

En Colombia ese cambio es más evidente y clarificador. La ayuda militar y económica norteamericana se destina especialmente a perseguir el narcotráfico y sólo en el último tiempo se ha empleado en forma limitada y con restricciones en el combate a la guerrilla. Esto último, cuando era evidente que la operación de la insurgencia guerrillera no podía disociarse totalmente de la actividad del narcotráfico.

El problema de la droga no se reduce a su producción y consumo. Es eso y mucho más. A su alrededor han surgido numerosas multinacionales del crimen que manejan cuantiosos recursos económicos, los que suman muchos miles de millones de dólares que se introducen en la economía de otros países con su secuela de corrupción, violencia y desestabilización.

El negocio no está sólo en el cultivo. Para producir la droga se requiere de precursores químicos en un volumen de tal magnitud que moviliza también enormes cantidades de dinero.

En Colombia, por ejemplo, se calcula en cien mil las hectáreas con plantaciones de coca. Sin embargo, para su transformación en cocaína se requiere de cuatro toneladas de precursores químicos por cada hectárea sembrada. Esos insumos, en su mayor porcentaje, no existen en el país, provienen del exterior y sus fabricantes se encuentran y operan en naciones de mayor desarrollo. Es decir, es mucho más lo que entra en precursores que lo que sale en droga.

El negocio, en consecuencia, sólo es posible con la participación de quienes proporcionan los elementos que permiten la elaboración de cocaína y otras drogas. Esta colaboración no es precisamente gratuita y da lugar a un tráfico voluminoso y moviliza igualmente inmensas sumas de dinero.

No obstante lo anterior, se habla y se sabe mucho de lo que ocurre en este y otros países productores, pero muy poco de lo que sucede en naciones de donde provienen los materiales que hacen posible transformar los cultivos en droga.

En otro orden, diversos estudios demuestran que la mayor parte del dinero que genera el narcotráfico se lava y se invierte fuera de Colombia. Este es otro aspecto que permanece en la penumbra y no es difícil imaginar que 
involucra a instituciones financieras y bancos que gozan de prestigio y general aceptación.

La conclusión es obvia. El combate a este flagelo, considerado una amenaza mundial, es tarea y responsabilidad de todos los países que de una u otra forma se ven involucrados, por albergar cultivos o elaborar droga en sus territorios, por sus niveles de consumo que los constituye en atractivos mercados, por ser originarios de los precursores químicos que permiten la producción de estupefacientes, por la utilización de sus instituciones financieras para el lavado y la inversión de dineros, por la permisividad de sus leyes o insuficientes controles que facilitan la operación de los narcotraficantes. En fin, son múltiples y variadas las formas de involucrarse como también son complejos y diversos los mecanismos de solución. Pero esto último sería materia de otra exposición y análisis.

Lo fundamental es que se entienda que todos deben colaborar en este esfuerzo, aún aquellos que hoy no se encuentran afectados, pero que mañana también pueden ser víctimas. A partir de este convencimiento se abren caminos para avanzar a soluciones reales y efectivas.

Nos anima la firme convicción que en la medida que se tenga éxito y el narcotráfico se bata en retirada, será menor la preocupación internacional por la situación interna de Colombia y progresivamente dejará de ser considerada una amenaza por otras naciones.

Estamos conscientes que lo anterior no resuelve toda la compleja y difícil problemática de este país, pero disminuiría notablemente la gravitación de uno de sus componentes más negativos y que provoca mayor rechazo.

\section{Una última reflexión}

En mi desempeño de poco más de dos años como Embajador de Chile en Colombia, he sostenido en más de una oportunidad que la imagen que los medios de difusión dan a conocer, revela sólo una parte de su realidad. No es una imagen falsa, pero si parcial y limitada, que pone el acento en los aspectos más negativos. Nos habla del narcotráfico, la guemilla, la violencia, de los secuestros, de los sicarios, de asesinatos y masacres, pero nada o muy poco nos dice de la otra Colombia. La de un país con una expresión cultural que la coloca junto a otras naciones a la vanguardia de América Latina. Con escrito- 
res, intelectuales y artistas de merecido prestigio internacional. Con profesionales altamente calificados. Con un sector empresarial pujante y competitivo. Con una clase trabajadora de elevada productividad. Con un nivel de investigación científica y tecnológica notable. En suma, la de una nación con una admirable riqueza humana que se refleja en su gente, espontánea y generosa, hospitalaria y abierta, con una enorme alegría de vivir.

Lo anterior explica el cariño que sienten por Colombia los que han tenido la oportunidad de conocer esa otra realidad. Este conocimiento nos permite apostar a la capacidad de su pueblo, para superar un presente incierto y conflictivo y construir un futuro de paz y prosperidad. 